\title{
The Utility of the BANA Test for Monitoring Anaerobic Infections due to Spirochetes (Treponema denticola) in Periodontal Disease
}

\author{
W.J. LOESCHE, J. GIORDANO, and P.P. HUJOEL
}

The University of Michigan School of Dentistry, Ann Arbor, Michigan 48109-1078

Treponema denticola, Porphyromonas gingivalis, and Bacteroides forsythus each possesses an enzyme(s) that hydrolyzes the synthetic substrate benzoyl-DL-arginine-naphthylamide (BANA). The presence of these organisms in a subgingival plaque sample can be determined by the ability of the plaque to hydrolyze BANA. In the present study, we describe the usefulness of the BANA test at various stages of a clinical trial of the efficacy of metronidazole in the treatment of periodontal disease. A BANA-positive test was significantly associated with high levels and proportions of spirochetes in the plaque, so that it provided information comparable with that which could be obtained by a microscopic examination of the plaque. Patients with such anaerobic spirochetal infections were randomly assigned to a group receiving either metronidazole or placebo ( $250 \mathrm{mg}$, three times a day) for one week and whose teeth were scaled and root-planed. The advantages of the decision that metronidazole be used were apparent from the comparison with the results obtained in the patients who received only the scaling and root planing. The initially BANA-positive teeth in the patients treated with metronidazole, scaling, and root planing gained attachment and exhibited a significant reduction in the need for periodontal surgery, when compared with the BANA-positive teeth in the patients who received only placebo, scaling, and root planing. After the conclusion of this therapy, those teeth with persistent BANA-positive plaques had significantly higher proportions and levels of spirochetes than did the teeth with BANA-negative plaques. A tooth site which tested BANA-positive after the initial therapy lost significantly more attachment in the year following active treatment than did a tooth site that tested BANA-negative, i.e., a mean difference of $0.48 \mathrm{~mm}$ per year. The ability of the BANA test to detect an anaerobic infection due to the BANA-positive species and possibly to predict future attachment loss indicates that this test may be helpful in the management of the periodontally diseased patient.

\section{J Dent Res 69(10):1696-1702, October, 1990}

\section{Introduction.}

The demonstration that most forms of periodontal disease can be associated with the presence and/or proportional overgrowth of a finite number of bacterial species has opened the possibility that these "infections" can be treated with specific antimicrobial therapies (Loesche, 1987). Any treatment paradigm involving antimicrobial agents should require that an infection be diagnosed and that the efficacy of treatment be monitored. The diagnosis of an infection by cultural methodologies is complicated by the anaerobic nature of the flora and the fastidious growth requirements of certain putative pathogens, such

Received for publication November 7, 1989

Accepted for publication May 29, 1990

This research was supported by grant No. DE06030 from the National Institute of Dental Research, and by a gift from Oral-B Laboratories, Redwood City, CA. as the spirochetes (Loesche, 1988) and Bacteroides forsythus (Wyss, 1989). Alternative methods to culturing, which may be more cost-efficient, have been suggested. They would include the microscopic examination of plaque for spirochetes and motile organisms (Listgarten and Helldén, 1978; Keyes and Rams, 1983); the use of highly specific polyclonal or monoclonal antibodies to the putative pathogens (Zambon et al., 1985; Bragd et al., 1987; Simonson et al., 1988); the use of whole genomic probes or oligodeoxynucleotide probes to ribosomal RNA to these organisms (Savitt et al., 1988; Giovannoni et al., 1988); or the detection of marker molecules, such as various enzymes, which are characteristic of some of the organisms (Syed et al., 1984; Loesche, 1986; Suido et al., 1987).

Treponema denticola (a small spirochete), Porphyromonas (Bacteroides) gingivalis, and Bacteroides forsythus each possesses an enzyme(s) that hydrolyzes the synthetic substrate benzoyl-DL-arginine-naphthylamide (BANA) (Loesche, 1986). Fifty-one other plaque species do not hydrolyze BANA, and several Capnocytophaga and non-pigmented Bacteroides species are variable in giving a weak BANA reaction (Loesche et al., 1990a). Because the three BANA-positive species are frequently cited as potential periodontal pathogens (Loesche, 1987; Moore, 1987; Dzink et al., 1988), and all are anaerobic organisms, the ability of a given subgingival plaque sample to hydrolyze BANA could be a measure of an anaerobic periodontal infection due to one or more of these species. BANA hydrolysis will detect $P$. gingivalis and/or $T$. denticola with a sensitivity of $92 \%$ and a specificity of $70 \%$ with highly specific polyclonal antibodies to these organisms in an ELISA assay being used as the reference standard (Loesche et al., 1990b). In untreated periodontal patients, BANA hydrolysis by subgingival plaques showed a sensitivity of $80 \%$ and a specificity of $98 \%$, when compared with a clinical judgment as to whether the sampled tooth site was periodontally healthy or diseased (Schmidt et al., 1988).

The present report is concerned with the possible usefulness of the BANA test in improving the diagnosis and/or treatment of periodontal disease. In particular, we were interested in the applications of the BANA test at various stages of a longitudinal clinical trial of the efficacy of metronidazole in periodontal disease. Could the BANA test be used for detection of a preponderance of the putative anaerobic pathogens in the plaque, and thereby allow the clinician to diagnose an anaerobic infection associated with these organisms? What would be the benefits and/or consequences if that diagnosis led to the use of metronidazole? Finally, what is the significance of a BANA-positive plaque sample after the teeth have been rigorously scaled and root-planed? Do such plaques reflect persistent infections and represent sites that will deteriorate in the foreseeable future?

\section{Materials and methods.}

Subjects. - Patients seen at the Graduate Periodontal Clinic who had an advanced form of adult periodontitis that would normally require periodontal surgery (and who had an anaer- 
obic periodontal infection, as judged by high proportions of spirochetes in three or four plaque samples), were entered into two double-blind studies involving the unsupervised one-week use of systemic metronidazole (Loesche et al., 1987a, 1988). Prospective patients who were pregnant, or had a history of drug allergies, or who were taking medication that could influence their periodontal condition (i.e., antibiotics, non-steroidal anti-inflammatory agents), were excluded from the study. Seventy-two patients completed the treatment phase of the study, and 55 of these patients were available for the one- and twoyear follow-up examinations.

Experimental protocol. - All patients received the treatment that is standard in the graduate clinic, i.e., rigorous debridement (scaling and root planing) of the teeth that had $3 \mathrm{~mm}$ or more probing depth, detailed oral hygiene instructions, and occlusal adjustment when indicated. In addition, the patients were randomly assigned to receive either metronidazole or placebo ( $250 \mathrm{mg}$, three times a day for one week). The medication was given either at the first week of scaling/root planing (first double-blind study) or after all scaling/root planing was completed (second double-blind study). The placement of the week of medication, either before or after debridement, did not have a significant effect on the microbiological outcomes (Loesche et al., 1990c). The experimental protocol was ethical, since subjects in the placebo group received all the scaling and root planing that would normally be delivered to patients attending our graduate clinic. In this sense, the placebo group was a positive control group, reflecting the clinical benefits that can be achieved by root-surface debridement, plus any benefits that might be associated with the participation in a double-blind clinical study.

All patients were evaluated for various clinical and bacteriological parameters prior to any treatment, again four to six weeks after the completion of all debridement and medication, and at annual intervals during the recall program. At each of these evaluations, the following information was collected: fullmouth probing depths and attachment levels about five sites (the disto-lingual site was not examined) of each tooth in the dentition (Ramfjord et al., 1973); cultural and microscopic analyses of the subgingival plaque removed from the most diseased tooth site in each quadrant; and the ability of these plaques to hydrolyze BANA. After the second treatment-planning session, any teeth that required periodontal surgery were given this treatment, and then these patients entered the recall program. In the recall program, the patients were given a prophylaxis and oral hygiene instructions by a dental hygienist at three-month intervals.

Furthermore, a periodontist who was not involved in the treatment of the patients, and who was unaware of which treatment group the patient was in, examined the patient, and, using the above clinical parameters and radiographs, determined the number of teeth that either needed periodontal surgery or needed to be extracted for periodontal purposes, at each of the four treatment planning sessions. The criteria used to determine the need for surgery at the second treatment planning session were: (1) presence or absence of bleeding; (2) presence or absence of exudate; (3) change in probing depth and attachment levels from those measured at the first treatment planning sessions; (4) root topography; (5) nature of bony defect or furcation involvement, as shown by radiographs as well as probing; and (6) whether surgical intervention was necessary so that better access for additional root instrumentation could be gained. In a separate investigation, two periodontists not involved in this study used these criteria to evaluate independently the periodontal surgical needs of 64 patients who were also not involved in the present study. The correlation coefficient for agreement between these two examiners was 0.82 , which was significant at the $p<0.0001$ level, indicating that the surgical criteria used were reproducible. The detailed clinical results of the effect of metronidazole on periodontal surgery will be reported elsewhere (Loesche et al., unpublished data).

Bacteriology. - The bacteriological procedures have been described (Loesche et al., 1984, 1985) and will be summarized. A periodontist selected the most periodontally-involved tooth in each quadrant, and these teeth were designated as bacteriological test teeth (Schmidt et al., 1988). The subgingival plaque from a discrete site on these test teeth was removed with a curette, added to a vial containing $0.5 \mathrm{~mL}$ of reduced transport fluid without EDTA, placed immediately into an anaerobic chamber, and dispersed for $20 \mathrm{~s}$ with a Vortex mixer. A $50-\mu \mathrm{L}$ portion was removed, and $10 \mu \mathrm{L}$ of this was placed on a glass slide, viewed by dark-field microscopy, and the number of spirochetes, selenomonads, motile rods, fusiforms, non-motile rods, and cocci was determined. The remaining $40 \mu \mathrm{L}$ was incubated overnight at $37^{\circ} \mathrm{C}$ in the presence of BANA, and any released naphthylamide was developed by the addition of fast garnet (Laughon et al., 1982). The remaining $450 \mu \mathrm{L}$ of the plaque suspension was diluted to $4 \mathrm{~mL}$, sonically dispersed for $20 \mathrm{~s}$ with a Kontes sonifier (Kontes Glass Co., Vineland, NJ), serially diluted in RTF, and plated automatically with a spiral plater (Spiral Systems Inc., Cincinnati, $\mathrm{OH}$ ) on a variety of selective and non-selective media.

Statistical analysis. -A two-factor ANOVA, with one fixed factor being the BANA result and one random factor being the patient, was performed in Table 1 for comparison of the bacteriological profiles of the plaque samples. For Tables 2 and 4 , the correlated binomial model was used to obtain the estimates of the proportion of bacteriological test sites where an event of interest (i.e., change in teeth needing surgery) occurred. This method takes into account the correlated nature of the observations made on test sites within patients, and the heterogeneity of total number of sites measured per patient

TABLE 1

MICROBIOLOGICAL PROFILE OF BANA-POSITIVE AND BANANEGATIVE PLAQUES AT ENTRY TO CLINICAL STUDY OF METRONIDAZOLE

\begin{tabular}{|c|c|c|c|}
\hline & $\begin{array}{c}\text { BANA- } \\
\text { Positive } \\
\mathrm{n}=224 \\
\end{array}$ & Significance & $\begin{array}{c}\text { BANA- } \\
\text { Negative } \\
\mathrm{n}=35 \\
\end{array}$ \\
\hline \multicolumn{4}{|l|}{ Microscopic } \\
\hline \% Spirochetes & 62.1 & $p=0.0001^{\mathrm{a}}$ & 39.5 \\
\hline$\%$ Rods & 16.3 & $\mathrm{p}=0.0001$ & 32.9 \\
\hline$\%$ Cocci & 3.6 & & 5.9 \\
\hline$\%$ Fusiforms & 4.7 & $p=0.009$ & 9.5 \\
\hline \% Selenomonads & 9.3 & & 7.7 \\
\hline$\%$ Motile & 3.2 & & 4.5 \\
\hline Bacteria/hpf & 26 & $p=0.006$ & 12 \\
\hline Spirochetes/hpf & 16.1 & $p<0.001$ & 4.7 \\
\hline \multicolumn{4}{|l|}{ Cultural } \\
\hline \% A. naeslundii & 1.1 & & 1.7 \\
\hline$\%$ A. viscosus & 2.2 & & 3.0 \\
\hline$\%$ A. odontolyticus & 0.4 & & 0.4 \\
\hline$\% S$. sanguis & 0.9 & & 2.1 \\
\hline$\%$ S. mutans & 0.7 & & 3.0 \\
\hline \% Veillonella & 0.5 & & 0.8 \\
\hline$\% F$. nucleatum & 3.9 & & 6.4 \\
\hline \% Selenomas sp. & 0.8 & & 0.2 \\
\hline$\%$ B. melaninogenicus & 1.0 & & 0.6 \\
\hline$\%$ B. intermedius & 9.6 & & 7.4 \\
\hline \% BANA neg Capnocytophaga sp. & 0.2 & & 0.1 \\
\hline \% BANA pos Capnocytophaga sp. & 0.2 & & 0.1 \\
\hline$\% P$. gingivalis & 0.9 & & 0.1 \\
\hline
\end{tabular}

(a) Difference between groups was significant when the two-factor ANOVA was used. 
TABLE 2

PROPORTION OF BANA-POSITIVE PLAQUES CONVERTING TO BANA-NEGATIVE PLAQUES FOLLOWING TWO DIFFERENT TREATMENT MODALITIES

\begin{tabular}{|c|c|c|c|c|c|c|}
\hline $\begin{array}{l}\text { Treatment } \\
\text { Modality }\end{array}$ & $\begin{array}{c}\text { No. of } \\
\text { Subjects }\end{array}$ & $\begin{array}{r}\mathrm{P} \\
\mathrm{Co} \\
\mathrm{BA}\end{array}$ & & $\begin{array}{c}\text { Within-patient } \\
\text { Correlation }\end{array}$ & $\begin{array}{c}\text { Ho: sites are } \\
\text { independent } \\
\text { Chi-square }\end{array}$ & Significance \\
\hline $\begin{array}{l}\text { Metronidazole }+ \\
\text { Scaling }+ \\
\text { Root Planing }\end{array}$ & 33 & $74 / 106^{\mathrm{a}}$ & $(70 \%)$ & $\begin{aligned} I & =0.191^{b} \\
& \pm 0.10\end{aligned}$ & 5.3 & $p=0.02$ \\
\hline $\begin{array}{l}\text { Placebo }+ \\
\text { Scaling }+ \\
\text { Root Planing } \\
\text { Treatment } \\
\text { Effect: significance }\end{array}$ & 39 & $\begin{array}{r}63 / 119^{a} \\
\text { chi-s }\end{array}$ & $(53 \%)$ & $\begin{aligned} r & =0.30^{b} \\
& \pm 0.13\end{aligned}$ & 6.5 & $p=0.01$ \\
\hline
\end{tabular}

(a) Number of plaque samples.

(b) $\mathrm{r}=$ within-patient correlation coefficient \pm standard error.

(Hujoel et al., 1990). Estimates of the proportions and their standard errors were obtained by use of maximum likelihood routines. The outcome of interest in Table 6 was the slope of the simple regression line obtained from the regression of attachment level measurements on time; a positive slope indicates a gain of attachment and a negative slope, a loss of attachment. A two-factor analysis of variance was performed, with the dependent variable being the regression coefficient, and the independent factors being the BANA result (positive or negative) (fixed factor) and the patient (random factor).

\section{Results.}

Table 1 shows the microbiological profile of BANA-positive and BANA-negative plaques removed from periodontally diseased teeth in patients who were recruited into the clinical trial of metronidazole. Eighty-six percent of these plaques were BANA-positive, and they differed from the BANA-negative plaques in that they had significantly higher proportions and levels of spirochetes per high-power microscopic field (hpf) and in total numbers of bacteria per hpf. The BANA-negative plaques had significantly higher proportions of rods and fusiforms. Within the spirochetes, the BANA reaction was significantly associated with the small-size spirochete $(p=0.009)$ and the intermediate size spirochete $(\mathrm{p}=0.04)$. T. denticola would be found in both of these groupings (Cheng et al., 1985). The proportions of $P$. gingivalis and BANA-positive Capnocytophaga species were low in both groups (Table 1). A positive BANA test in a plaque sample thus indicated high levels of spirochetes, presumably high levels of $T$. denticola, and provided the same information about spirochetes as could be obtained by the microscopic examination of plaques.

A positive BANA test could be used so that an anaerobic infection associated with spirochetes and/or $T$. denticola could be diagnosed. Metronidazole is an antimicrobial agent whose spectrum of activity is limited to anaerobes (Tally et al., 1978) and would be an indicated treatment choice for infections involving anaerobic organisms such as the spirochetes. If metronidazole were the drug of choice in anaerobic periodontal infections, then those patients receiving it should exhibit benefits (in regard to both their anaerobic infection and the clinical appearance of their periodontium) that would be above and beyond those associated with routine scaling and root planing. We then sought to determine what magnitude of benefits would accrue to those patients who received systemic metronidazole based on a positive BANA reaction. So that these determinations would be made objectively, the observations were made in conjunction with a double-blind clinical trial of metronidazole, in which the patients were randomly assigned to a metronidazole or placebo medication superimposed upon a regimen of scaling and root planing.

In patients treated with metronidazole plus scaling and root planing, $70 \%$ of the BANA-positive plaques converted to BANA-negative, whereas in the positive control group, $53 \%$ of the BANA-positive plaques converted to BANA-negative (Table 2). There was a significant within-patient correlation in both groups, indicating that if one tooth site converted from BANA-positive to BANA-negative, then there was an increased probability that other sites in the same mouth would also go from positive to negative (Table 2). After the withinpatient correlation was accounted for, the conversion to BANAnegative plaques was significantly greater in the metronidazole group, indicating a treatment effect (chi-square, 4.54; $\mathrm{p}=$ 0.032 ) (Table 2). This conversion was associated with a significantly greater reduction in proportions of spirochetes in the subgingival plaques in the metronidazole group, relative to the

TABLE 3

EFFECT OF SCALING AND ROOT PLANING PLUS EITHER METRONIDAZOLE OR PLACEBO MEDICATION ON LEVELS OF BANAPOSITIVE PLAQUE ORGANISMS

\begin{tabular}{|c|c|c|c|c|c|}
\hline \multirow{3}{*}{$\begin{array}{l}\text { BANA-Positive } \\
\text { Organisms }\end{array}$} & \multicolumn{2}{|c|}{$\begin{array}{l}\text { 1st Treatment-planning } \\
\text { Session }\end{array}$} & \multicolumn{3}{|c|}{$\begin{array}{l}\text { 2nd Treatment-planning } \\
\text { Session }\end{array}$} \\
\hline & Metronidazole & Placebo & Metronidazole & & Placebo \\
\hline & $\mathrm{n}=33^{\mathrm{c}}$ & $\mathrm{n}=39$ & $n=33$ & & $\mathrm{n}=\mathbf{3 9}$ \\
\hline Spirochetes $^{\mathrm{a}}$ & $55.1 \%$ & $59.5 \%$ & $27.7 \%$ & $\mathrm{p}=0.002^{\mathrm{d}}$ & $41.3 \%$ \\
\hline P. gingivalis ${ }^{b}$ & 0.3 & 1.8 & 0.3 & & 0.2 \\
\hline Capnocytophaga sp. & 0.2 & 0.1 & 0.1 & & 0.5 \\
\hline
\end{tabular}

(a) Percentage of the microscopic count.

(b) Percentage of the viable count.

(c) $\mathrm{n}=$ number of patients.

(d) Difference between groups was significant when the two-sample test for promotions was used. 
TABLE 4

PROPORTION OF BANA-POSITIVE SITES THAT EXPERIENCED A REDUCTION IN SURGICAL NEED FOLLOWING TWO DIFFERENT TREATMENT MODALITIES

\begin{tabular}{|c|c|c|c|c|c|c|}
\hline $\begin{array}{l}\text { Treatment } \\
\text { Modality }\end{array}$ & $\begin{array}{c}\text { No. of } \\
\text { Subjects }\end{array}$ & \multicolumn{2}{|c|}{$\begin{array}{l}\text { Proportion not } \\
\text { Needing Surgery }\end{array}$} & $\begin{array}{l}\text { Within-patient } \\
\text { Correlation }\end{array}$ & $\begin{array}{c}\text { Ho: sites are } \\
\text { independent } \\
\text { Chi-square }\end{array}$ & Significance \\
\hline $\begin{array}{l}\text { Metronidazole + } \\
\text { Scaling }+ \\
\text { Root Planing }\end{array}$ & 32 & $49 / 108^{a}$ & $(45 \%)$ & $\begin{aligned} r & =0.301^{b} \\
& \pm 0.10\end{aligned}$ & 8.84 & $p<0.003$ \\
\hline $\begin{array}{l}\text { Placebo }+ \\
\text { Scaling }+ \\
\text { Root Planing }\end{array}$ & 34 & $19 / 91^{\mathrm{a}}$ & $(21 \%)$ & $\begin{aligned} r & =0.35^{\mathrm{b}} \\
& \pm 0.10\end{aligned}$ & 10.07 & $p<0.001$ \\
\hline $\begin{array}{l}\text { Treatment } \\
\text { Effect: significance }\end{array}$ & & chi-sc & & & & \\
\hline
\end{tabular}

(a) Number of teeth.

(b) $\mathrm{r}=$ within-patient correlation coefficient \pm standard error.

positive control group (Table 3 ). Thus, the combination of scaling/root planing and metronidazole reduced the proportion of spirochetes from $55 \%$ to $28 \%$, whereas the combination of scaling/root planing and placebo reduced the proportion of spirochetes from $60 \%$ to $41 \%$. The BANA-positive $P$. gingivalis and Capnocytophaga species were minor members of the cultivable flora in both treatment groups, and their proportions did not change appreciably as a result of treatment (Table 3 ).

We next looked for clinical correlates of this metronidazole effect only in those teeth that were initially BANA-positive. One approach was the determination of whether the treatment affected the need for periodontal surgery. At baseline, a total of 225 sites tested BANA-positive, and 199 of these were judged to be in eventual need of periodontal surgery. Many of these teeth improved as a result of the various treatments, to the extent that they did not need any surgical intervention at the second treatment-planning session. In the metronidazoletreated patients, $45 \%$ of the teeth that were initially BANApositive and recommended for surgery no longer required surgery at the second treatment-planning session, whereas in the positive control patients, $21 \%$ of similar teeth no longer required surgery (Table 4). This difference between treatment groups was highly significant at the $p=0.005$ level (Table 4). When the analysis was performed on those teeth that were initially BANA-negative, there was no statistically significant difference between the treatment groups. Thus, the reduction in surgery was from 12 to five teeth in the metronidazole group and from 14 to eight teeth in the positive control group.

A BANA-positive plaque at the second treatment-planning session, regardless of the treatment group to which the patient belonged, indicated high proportions and levels of spirochetes (Table 5). In the 83 plaques that were BANA-positive at both the first and second treatment-planning sessions, the treatments caused a slight reduction in the proportions of spirochetes and reduced the levels of spirochetes per hpf by about $55 \%$. But in the 114 plaques that were BANA-positive at the first treatment-planning session and that converted to BANA-negative at the second treatment-planning session, the treatment caused a highly significant reduction in proportions of spirochetes and a $90 \%$ reduction in the levels of spirochetes per hpf (Table 5). Thus, a BANA-positive plaque at the completion of treatment indicated an inadequate resolution of the spirochetal infection.

We were interested in the future periodontal health of these BANA-positive teeth relative to the BANA-negative teeth, given the fact that there were about six times more spirochetes remaining on the surfaces of the BANA-positive teeth, compared with the BANA-negative teeth (Table 5). The average probing depths and attachment levels were plotted over time for the BANA-positive and BANA-negative teeth, i.e., for those teeth present at the second, third, and fourth annual treatment-planning sessions. There were no significant differences in the probing-depth measurements over time for the 175 teeth that

TABLE 5

EFFECT OF TREATMENT UPON THE BANA-POSITIVE STATUS OF PLAQUES REMOVED FROM DISCRETE TOOTH SITES

\begin{tabular}{|c|c|c|c|c|c|}
\hline & \multicolumn{2}{|c|}{$\begin{array}{c}\text { Sites which Convert to BANA-negative at Second } \\
\text { Treatment-planning Session } \\
\end{array}$} & & \multicolumn{2}{|c|}{$\begin{array}{c}\text { Sites which Remain BANA-positive at Second } \\
\text { Treatment-planning Session }\end{array}$} \\
\hline & $\begin{array}{c}\text { BANA-positive } \\
\text { 1st Treatment-planning } \\
\text { Session } \\
\mathrm{n}=114 \\
\end{array}$ & $\begin{array}{c}\text { BANA-negative } \\
\text { 2nd Treatment-planning } \\
\text { Session } \\
\mathrm{n}=114 \\
\end{array}$ & & $\begin{array}{c}\text { BANA-positive } \\
\text { 1st Treatment-planning } \\
\text { Session } \\
\mathrm{n}=83 \\
\end{array}$ & $\begin{array}{c}\text { BANA-positive } \\
\text { 2nd Treatment-planning } \\
\text { Session } \\
\mathrm{n}=83 \\
\end{array}$ \\
\hline $\begin{array}{l}\text { \% Spirochetes } \\
\text { Difference }\end{array}$ & 62.5 & $\begin{array}{c}25.8^{\mathrm{a}} \\
37.7 \%\end{array}$ & $p<0.0001$ & 61.5 & $\begin{array}{l}48.6^{\circ} \\
12.9\end{array}$ \\
\hline $\begin{array}{l}\text { \% P. gingivalis } \\
\text { Difference }\end{array}$ & 0.4 & $\begin{array}{l}0.06 \\
0.34\end{array}$ & & 1.2 & $\begin{array}{l}0.6 \\
0.6\end{array}$ \\
\hline $\begin{array}{l}\text { \% Capnocytophaga sp. } \\
\text { Difference }\end{array}$ & 0.12 & $\begin{array}{l}0.08 \\
0.04\end{array}$ & & 0.05 & 0.05 \\
\hline $\begin{array}{l}\text { Bacteria/hpf } \\
\text { Difference }\end{array}$ & 22.4 & $\begin{array}{c}5.9^{\mathrm{a}} \\
16.5\end{array}$ & & 33.6 & $\begin{array}{l}19.1^{\mathrm{a}} \\
14.5\end{array}$ \\
\hline $\begin{array}{l}\text { Spirochetes } / \mathrm{hpf} \\
\text { Difference }\end{array}$ & 14.0 & $1.5^{\mathrm{a}}$ & & 20.7 & $\begin{array}{r}9.3^{\mathrm{a}} \\
11.4\end{array}$ \\
\hline
\end{tabular}

(a) Values between groups at second treatment-planning session are significantly different $(p<0.01)$. 
TABLE 6

THE RELATIONSHIP BETWEEN BANA STATUS AFTER INITIAL THERAPY AND FUTURE ATTACHMENT LOSS

\begin{tabular}{|c|c|c|c|}
\hline \multicolumn{4}{|c|}{ First Year Only } \\
\hline $\begin{array}{l}\text { BANA Status } \\
\text { Patient } \\
\text { Error }\end{array}$ & $\begin{array}{r}\mathrm{df} \\
1 \\
53 \\
121\end{array}$ & $\begin{array}{c}\text { ss } \\
0.0084 \\
0.1770 \\
0.1944\end{array}$ & $\begin{aligned} F \text { value } & =5.21 \\
p & =0.024\end{aligned}$ \\
\hline $\begin{array}{l}\text { BANA-positive sites } \\
\text { BANA-negative sites }\end{array}$ & & $\begin{array}{l}\mathrm{n}=57 \\
\mathrm{n}=119\end{array}$ & $\begin{array}{c}\text { Mean loss per Year } \\
-0.48 \mathrm{~mm} \\
0.00 \\
0 . \overline{48 \mathrm{~mm}}\end{array}$ \\
\hline & \multicolumn{2}{|c|}{$\begin{array}{l}\text { First, Second, or } \\
\text { Third Year }\end{array}$} & \\
\hline $\begin{array}{l}\text { BANA Status } \\
\text { Patient } \\
\text { Error }\end{array}$ & $\begin{array}{r}\text { df } \\
1 \\
54 \\
123\end{array}$ & $\begin{array}{c}\text { ss } \\
0.0069 \\
0.1698 \\
0.1665\end{array}$ & $\begin{aligned} F \text { value }= & 5.14 \\
p & =0.025\end{aligned}$ \\
\hline $\begin{array}{l}\text { BANA-positive sites } \\
\text { BANA-negative sites }\end{array}$ & & $\begin{array}{l}\mathrm{n}=59 \\
\mathrm{n}=120\end{array}$ & $\begin{array}{c}\text { Mean loss per year } \\
-0.33 \mathrm{~mm} \\
\frac{0.05}{0.38 \mathrm{~mm}}\end{array}$ \\
\hline
\end{tabular}

$\mathrm{df}=$ Degrees of freedom; $s s=$ sum of squares.

were monitored in 54 patients. However, there was a significant difference in the attachment levels between BANA-positive and BANA-negative teeth. The teeth that were BANApositive at the second treatment-planning session lost, on the average, $0.48 \mathrm{~mm}$ of attachment during the year following active treatment, whereas in the teeth that were BANA-negative, there was no discernible loss (Table 6). When the analyses were extended so that data could be taken in from the first and second, and, if available, the third annual treatmentplanning sessions, the BANA-positive teeth lost, on the average, $0.38 \mathrm{~mm}$ of attachment (per year) more than the BANAnegative teeth. This difference was significant $(p=0.025$, Table 6).

\section{Discussion.}

A diagnostic test should be useful, ideally leading to a choice of treatment that would confer benefits upon the patient. Very few diagnostic tests exist for periodontal disease. Microscopic examinations of plaque samples have been used in the detection of high levels and/or proportions of spirochetes (Listgarten and Helldén, 1978), which can then be used for diagnosis of an anaerobic spirochetal infection (Loesche, 1988), or to monitor the need for periodontal treatment (Listgarten and Levin, 1981). In this study, we sought to determine whether the BANA test could substitute for a microscopic count in yielding diagnostic information regarding the levels and proportions of $\mathrm{spi}$ rochetes and other BANA-positive species in plaques removed from tooth sites that had been judged by a periodontist as being the worst and/or the most representative of the periodontally diseased sites in each quadrant.

$T$. denticola, as measured indirectly as a small/intermediatesized spirochete, was the only known BANA-positive species monitored that could be associated with a BANA-positive reaction in the plaque. $P$. gingivalis and the BANA-positive Capnocytophaga species were present in low and similar proportions in both the BANA-positive and BANA-negative plaques (Table 1), and could not be associated with the BANA reaction. B. forsythus was not monitored in this investigation because of the difficulty in the detection of this organism on primary isolation plates (Gmür et al., 1989), and because spe- cific antibodies and/or DNA probes to this organism were not available at the time of this investigation. Recent studies in which plaques were monitored by immunological reagents to $T$. denticola, $P$. gingivalis, and $B$. forsythus suggest that $B$. forsythus can be a contributor to the BANA reaction (Bretz et al., unpublished results).

Although the spirochetes were significantly elevated in the BANA-positive plaques relative to the BANA-negative plaques, there still were impressive numbers of spirochetes in the BANAnegative plaques, i.e., $39.5 \%$ spirochetes and 4.7 spirochetes per hpf (Table 1). The absence of a positive BANA reaction in the presence of what would appear to be adequate numbers of spirochetes would suggest that $T$. denticola, the only spirochete known to be BANA-positive, was not present in high numbers in these plaques. If this be true, and if $T$. denticola is more of a periodontopathogen than the other plaque spirochetes (Loesche, 1988), then the BANA test could provide more diagnostic information than can be obtained by a microscopic examination for spirochetes.

The present findings agree with previous findings that showed a strong relationship between a BANA-positive reaction and high levels of plaque spirochetes (Bretz and Loesche, 1987; Loesche et al., 1987b). However, there is the possibility that other plaque species, and possibly host enzymes, could be contributing to this reaction. We have screened approximately 244 strains representing 51 species (including $T$. vincentii, $T$. pectinovorum, an unspeciated treponemal species, and four black-pigmented bacteroides species that could be present in plaque), and found them uniformly BANA-negative (Loesche et al., 1990a). A variable reaction was observed with certain Bacteroides and Capnocytophaga species in which 36 of 152 separate determinations were positive or weakly positive, but these reactions usually occurred with numbers of organisms, i.e., $10^{8} \mathrm{CFU}$, that were beyond their expected levels in a $\mathrm{mg}$ of plaque. In the present investigation, the Capnocytophaga species were monitored and did not seem to be contributing to the BANA-positive reaction in the plaque (Tables 1,3 , and 5 ). There was no convenient way to monitor the BANA-variable Bacteroides species, such as B. capillosus, B. denticola, and $B$. oralis, so their contributions to the observed BANApositive reactions are not known. Thus, we think it unlikely that other plaque species were contributing to the BANA reaction.

The plaque sample is often contaminated with gingival crevicular fluid (GCF) and/or blood, and these fluids contain proteolytic enzymes of host origin that could potentially hydrolyze BANA. We have not found blood, saliva, or neutrophils isolated from the blood or from gingival crevicular washings to be able to hydrolyze BANA (Bretz and Loesche, 1987; Loesche et al., 1987b). Recent reports have shown that GCF that was pooled from multiple patients had a trypsin-like activity, as measured by the hydrolysis of peptide derivatives of 7-amino4-trifluoromethyl coumarin (AFC) (Cox and Eley, 1989a, b). This AFC-hydrolytic enzyme(s) is presumably of host origin and could be present in plaque samples. We, however, have found that when portions of the same plaque sample are exposed to either BANA or z-Arg-AFC, only the hydrolysis of BANA could be significantly associated with the plaque proportions of spirochetes (Schmidt et al., 1988). Thus, the enzyme in the plaque that hydrolyzed the AFC substrate and is possibly the tryptase enzyme (Cox and Eley, 1989a) bore no relationship to the plaque levels of spirochetes.

Another reason for the suspicion that the host's proteolytic enzymes would not be important contributors to the proteolytic activity of subgingival plaque samples is simply one of quantitation. These host enzymes were detected in a GCF sample that was pooled from 20 patients, with from about 2 to $13 \mu \mathrm{L}$ of GCF collected per patient (Cox and Eley, 1989b). This 
would amount to from 40 to $260 \mathrm{mg}$ of GCF. Our plaque samples weighed between 1 and $2 \mathrm{mg}$, and if they contained as much as $10 \% \mathrm{GCF}$, this would amount to from 0.1 to 0.2 $\mathrm{mg}$ of GCF. Since our BANA reactions were performed on about one-tenth of the plaque sample, at most, from 10 to 20 $\mu \mathrm{g}$ of GCF would be present, which is from 4000 - to 13,000 fold less GCF than had been used for the demonstration of the host's proteolytic enzymes in GCF (Cox and Eley, 1989b).

The utility of the BANA test was shown in the double-blind study involving metronidazole. A positive BANA test provided the scientific basis for the selection of this particular antimicrobial agent. The advantages of our decision to use metronidazole in the presence of an anaerobic infection are apparent from the comparison with the clinical results obtained in the positive control patients (Tables 2 and 4). The positive control patients received the type of therapy that is routinely given to patients classified as American Dental Association types III and IV periodontal patients, and their clinical response should reflect the improvements that are typical of this standard form of treatment. Any improvements beyond this level should reflect the metronidazole, given the double-blind nature of the study. Since three to four plaques were sampled in each patient, it was necessary to take into account the fact that sites nested within a patient could be influenced by a host factor. This was done by use of the correlated binomial model, which takes into account the correlated nature of sites within a patient and the heterogeneity of the total number of sites measured per patient (Hujoel et al., 1990). The highly significant effect of the host factor on the conversion of BANA-positive plaques to BANA-negative plaques (Table 2) and the reduction in surgical needs (Table 4) illustrate the need for the host factor to be taken into account. It indicates that certain intrinsic (immunological factors) or extrinsic (compliance, oral hygiene) host factors determine the tooth-specific response to a certain extent.

After the host factor and the positive effects of scaling and root planing were accounted for, a treatment effect due to the unsupervised usage of metronidazole was evident. The metronidazole was associated with a significant reduction in the proportions and levels of spirochetes (Table 3 ), a significant conversion of BANA-positive plaques to BANA-negative plaques (Table 2), and a significant reduction in the need for periodontal surgery (Table 4). Thus, an important utility of the BANA test would be its ability to allow the clinician to make a diagnosis of an anaerobic infection, which in turn would enable the clinician, by prescribing metronidazole as part of the treatment, to achieve clinical benefits for the patient that were beyond those that could be achieved by scaling and rootplaning alone.

A tooth site with a BANA-positive plaque at the conclusion of the medication and the scaling/root planing had significantly higher proportions of spirochetes than did a tooth site with a BANA-negative plaque (Table 5). Such BANA-positive teeth could possibly experience more periodontal disease in the foreseeable future than teeth with BANA-negative plaques, if one assumes that the high proportions of spirochetes indicated a residual infection with these putative periodontopathogens. In the present investigation, the tooth sites that were BANA-positive at the second treatment-planning session lost significantly more attachment than did the BANA-negative tooth sites when examined during the recall period at one year, and at two and three years after active treatment (Table 6).

Other investigators have been unable to show that clinical parameters such as probing depths, attachment levels, and bleeding on probing, among others, were of value in the prediction of future attachment loss in untreated periodontal patients (Haffajee et al., 1983; Lang et al., 1986; Badersten et al., 1987). Listgarten and Levin (1981) were able to show that the proportions of spirochetes in pooled plaque samples, but not clinical parameters, facilitated the prediction of which patients, in the absence of maintenance therapy, would relapse following active periodontal therapy. Our finding that a positive BANA test, following initial therapy, is indicative of future attachment loss during recall, is similar to the Listgarten and Levin report, since the BANA test was positively correlated with plaque levels and proportions of spirochetes (Table 5) (Loesche et al., 1987b).

The possibility that a positive BANA test is associated with future attachment loss is a finding of potentially great clinical significance and needs to be carefully scrutinized. Among the criticisms that can be offered are those relating to the statistical model that was used. In this model, a complex, correlated observation vector of attachment loss over time is reduced to a unidimensional response, the regression slope. A linear model implies that periodontal disease progression is linear, whereas it may be exponential, or occur in random bursts of activity (Goodson, 1986) or as asynchronous multiple bursts (Haffajee and Socransky, 1986). The statistical methodology used may not be efficient for showing the effect of time-dependent covariates, such as the host-flora interactions that can occur in the pocket ecosystem. Also, the results discussed in this paper make inference toward the most diseased sites in each quadrant. The sites were selected by expert choice of a periodontist as being the most representative of the periodontally diseased sites in each quadrant. The sampling technique is a "purposive" or "judgment" sample, and care should be taken in extrapolation of these results to other sites. For instance, these results should not be extrapolated to the BANA results obtained in gingivitis sites or to sites that were randomly chosen in the dentition.

The other models that have been proposed to explain progression of periodontal disease, i.e., the random burst and/or the asynchronous multiple burst model, also have problems in interpretation (Fleiss et al., 1988). Attachment loss that occurs in bursts of $2 \mathrm{~mm}$ or more have large error rates to the extent that one-third of the bursts may be false-positive (Gunsolley and Best, 1988; Cohen and Ralls, 1988). A high cut-off point, such as $2 \mathrm{~mm}$ or more attachment loss, results in high specificity, low sensitivity, and rare disease (Aeppli et al., 1985). Thus, while the linear progression model used for prediction of attachment loss in this study is not without problems, it does represent a useful way for detection of low magnitude changes in attachment that may reflect how some attachment is lost in periodontal disease.

Also, the role of surgery in this outcome needs to be evaluated. Approximately $66 \%$ of the BANA-positive test teeth and $54 \%$ of the BANA-negative test teeth went on to have Widman flap surgery, and then they, and the non-surgically treated test teeth, were followed for one or more years. Surgery and concomitant root planing presumably should have converted the remaining BANA-positive teeth to BANA-negative, and this would mitigate against the BANA-positive teeth exhibiting future attachment loss. On the other hand, surgery, even though it was conservative and did not involve osseous re-contouring, could have had an adverse effect on attachment levels that would appear at the annual treatment-planning sessions during the recall period. Since, there was a higher proportion of BANA-positive teeth than BANA-negative teeth experiencing surgery, there is the possibility that if surgery had an adverse effect on attachment levels, this could contribute to why the BANA-positive teeth tended to lose more attachment than the BANA-negative teeth. However, since the Widman flap surgery that was performed in these patients is reported to maintain or actually increase attachment levels in pockets initially $\geq 6 \mathrm{~mm}$ (Knowles et al., 1979; Lindhe et al., 1982; Pihlstrom et al., 1984), this possibility would not appear likely. 
The results reported in this investigation imply that the BANA test has multiple utilities in periodontal disease that would facilitate patient management. A direct estimate of this usefulness ideally would require a randomized clinical trial in which one group was managed with access to the BANA data, whereas the other group was managed without such information (Begg, 1987). A trial such as this would provide estimates on the influence of the diagnostic test on the subsequent patient management and on the disease progression. The BANA test as described in this paper is not convenient for such field tests, but a solid-state modification of the BANA test, which provides comparable results within $15 \mathrm{~min}$ at chairside (Loesche et al., 1990b), could be evaluated in this regard.

\section{Acknowledgments.}

We acknowledge the assistance of Dr. Billy A. Smith in the decisions as to whether teeth needed surgery or not, Janice Stoll for the microbiology and BANA readings, and Carol Gerlach for the preparation of the manuscript.

\section{REFERENCES}

AEPPLI, D.M.; BANDT, C.L.; and BOEN, J.R. (1985): Measuring and Interpreting Increases in Probing Depth and Attachment Loss, J Periodoniol 56:262-264.

BADERSTEN, A.; NILVEUS, R.; and EGELBERG, J. (1987): Effect of Nonsurgical Periodontal Therapy. (VIII) Probing Attachment Changes Related to Clinical Characteristics, $J$ Clin Periodontol 14:425-432.

BEGG, C.B. (1987): Biases in the Assessment of Diagnostic Tests, Stat Med 6:411423.

BRAGD, L.; DAHLEN, G.; WIKSTROM, M.; and SLOTS, J. (1987): The Capability of Actinobacillus actinomycetemcomitans, Bacteroides gingivalis and Bacteroides intermedius to Indicate Progressive Periodontitis, a Retrospective Study, J Clin Periodontol 14:95-99.

BRETZ, W.A. and LOESCHE, W.J. (1987): Characteristics of Trypsin-like Activity in Subgingival Plaque Samples, $J$ Dent Res 66:1668-1672.

CHENG, S.L.; SIBOO, R.; CHIN QUEE, T.; JOHNSON, J.L.; MAYBERRY, W.R.; and CHAN, E.C.S. (1985): Comparative Study of Six Random Oral Spirochete Isolates, J Periodont Res 20:602-612.

COHEN, M.E. and RALLS, S. (1988): False Positive Rates in the Determination of Changes in Probing Depth-related Periodontal Measurements, $J$ Periodont Res 23:161-165.

COX, S.W. and ELEY, B.M. (1989a): Tryptase-like Activity in Crevicular Fluid from Gingivitis and Periodontitis Patients, J Periodont Res 24:41-44.

COX, S.W. and ELEY, B.M. (1989b): Detection of Cathepsin B- and LElastase-, Tryptase-, Trypsin-, and Dipeptidyl Peptidases IV-like Activities in Crevicular Fluid from Gingivitis and Periodontitis Patients with Peptidyl Derivatives of 7-amino-4-trifluoromethyl Coumarin, $J$ Periodont Res 24:353-361.

DZINK, J.L.; SOCRANSKY, S.S.; and HAFFAJEE, A.D. (1988): The Predominant Cultivable Microbiota of Active and Inactive Lesions of Destructive Periodontal Diseases, $J$ Clin Periodontol 15:316-323.

FLEISS, J.L.; WALLENSTEIN, S.; CHILTON, N.W.; and GOODSON, J.M. (1988): A Re-examination of Within Mouth Correlations of Attachment Level and Changes in Attachment Level, $J$ Clin Periodontol 15:411-416.

GIOVANNONI, S.J.; DELONG, E.F.; OLSEN, G.J.; and PACE, N.R. (1988): Phylogenetic Group-Specific Oligodeoxynucleotide Probes for Identification of Single Microbial Cells, $J$ Bacteriol 170:720-726.

GMÜR, R.; STRUB, J.R.; and GUGGENHEIM, B. (1989): Prevalence of Bacteroides forsythus and Bacteroides gingivalis in Subgingival Plaque of Prosthodontically treated Patients on Short Recall, $J$ Periodont Res 24:113-120.

GOODSON, J.M. (1986): Clinical Measurements of Periodontitis, J Clin Periodontol $13: 446-460$.

GUNSOLLEY, J.C. and BEST, A.M. (1988): Change in Attachment Level, $J$ Periodontol 59:450-452.

HAFFAJEE, A.D. and SOCRANSKY, S.S. (1986): Attachment Level Changes in Destructive Periodontal Diseases, $J$ Clin Periodontol 13:461-475.

HAFFAJEE, A.D.; SOCRANSKY, S.S.; and GOODSON, J.M. (1983): Clinical Parameters as Predictors of Destructive Periodontal Disease Activity, $J$ Clin Periodontol 10:257-265.

HUJOEL, P.; MOULTON, L.; and LOESCHE, W.J. (1990): Estimation of Sensitivity and Specificity of Site-specific Diagnostic Tests, J Periodont Res 25:193-196.

KEYES, P.H. and RAMS, R.E. (1983): A Rationale for the Management of Periodontal Diseases: Rapid Identification of Microbial "Therapeutic Targets" with Phase-Contrast Microscopy, $J$ Am Dent Assoc 106:803-812.

KNOWLES, J.W.; BURGETT, F.G.; NISSLE, R.R.; SHICK, R.A.; MORRISON, E.C.; and RAMFJORD, S. (1979): Results of Periodontal Treatment Related to Pocket Depth and Attachment Level, J Periodontol 50:225-233.

LANG, N.P.; JOSS, A.; ORSANIC, T.; GUSBERTI, F.A.; and SIEGRIST, O.E. (1986): Blecding on Probing. A Predictor for the Progression of Periodontal Disease, $J$ Clin Periodontol 13:590-596.

LAUGHON, B.E.; SYED, S.A.; and LOESCHE, W.J. (1982): API-ZYM System for Identification of Bacteroides sp., Capnocytophaga sp. and Spirochetes of Oral Origin, $J$ Clin Microbiol 15:97-102.

LINDHE, J.; WESTFELT, E.; NYMAN, S.; SOCRANSKY, S.S.; HEUL, L.; and BRATTHALL, G. (1982): Healing Following Surgical/Nonsurgical Treatment of Periodontal Disease. A Clinical Study, $J$ Clin Periodontol 9:115-128.

LISTGARTEN, M.A. and HELLDÉN, L. (1978): Relative Distribution of Bacteria at Clinically Healthy and Periodontally Diseased Sites in Humans, J Clin Periodontol 5:115-132.

LISTGARTEN, M.A. and LEVIN, S. (1981): Positive Correlation Between the Proportions of Subgingival Spirochetes and Motile Bacteria and Susceptibility of Human Subjects to Periodontal Deterioration, J Clin Periodontol 8:122-138.

LOESCHE, W.J. (1986): The Identification of Bacteria Associated with Periodontal Disease and Dental Caries by Enzymatic Methods, Oral Microbiol Immunol $1: 65-70$.

LOESCHE, W.J. (1987): The Bacterial Etiology of Periodontal Disease: The Specific Plaque Hypothesis. In: Clinical Dentistry, J.W. Clark, Ed., Philadelphia: Harper \& Row, pp. 11-20.

LOESCHE, W.J. (1988): The Role of Spirochetes in Periodontal Disease, Adv Den Res 2:275-283.

LOESCHE, W.J.; BRETZ, W.A.; KERSCHENSTEINER, D.; STOLL, J.; SO CRANSKY, S.S.; HUJOEL, P.P.; and LOPATIN, D.E. (1990a): The Development of a Diagnostic Test for Anaerobic Periodontal Infections Based upon Plaque Hydrolysis of Benzoyl-DL-Arginine Naphthylamide (BANA), J Clin Microbiol 28:1551-1559.

LOESCHE, W.J.; BRETZ, W.A.; LOPATIN, D.; STOLL, J.; RAU, C.F.; HILLENBURG, K.C.; KILLOY, W.J.; DRISKO, C.L.; WILLIAMS, R.; WEBER H.P. CLARK, W.; MAGNUSSON, I.; WALKER, C.; and HUJOEL, P.P. (1990b): Multi-Center Clinical Evaluation of a Chairside Method for Detecting Certain Pcriodontopathic Bacteria in Periodontal Disease, $J$ Periodontol 61:189-196.

LOESCHE, W.J.; GIORDANO, J.; and HUJOEL, P.P. (1990c): Metronidazole in Periodontitis: Effect of Placement of Medication on Clinical and Bacteriological Parameters, J Dent Res 69:276, Abst. No. 1343.

LOESCHE, W.J.; GIORDANO, J.; SCHWARCZ, J.; SMITH, B.; and CAFFESSE R.G. (1988): A Double-blind Clinical Trial of Metronidazole in Periodontitis, $J$ Dent Res 67:245, Abst. No. 1059.

LOESCHE, W.J. and HUJOEL, P. (1990): Microbiological-based Diagnostic Tests for Periodontitis. Considerations in Regard to Sensitivity, Specificity and Accuracy. In: Markers of Disease Susceptibility and Activity for Periodontal Disease, N.W. Johnson, Ed., Cambridge; Cambridge University Press (in press).

LOESCHE, W.J.; SCHMIDT, E.; SMITH, B.A.; CAFFESSE, R.; and STOLL J. (1987a): Metronidazole Therapy for Periodontitis, J Periodont Res 22:224-226. LOESCHE, W.J.; SYED, S.A.; MORRISON, E.C.; KERRY, G.A.; HIGGINS, T.; and STOLL, J. (1984): Metronidazole in Periodontitis. I. Clinical and Bacteriological Results After 15 to 30 Weeks, $J$ Periodontol 55:325-335.

LOESCHE, W.J.; SYED, S.A.; SCHMIDT, E.; and MORRISON, E.C. (1985): Bacterial Profiles of Subgingival Plaques in Periodontitis, $J$ Periodontol 56:447-456.

LOESCHE, W.J.; SYED, S.A.; and STOLL, J. (1987b): Trypsin-like Activity in Subgingival Plaque: a Diagnostic Marker for Spirochetes and Periodontal Disease? I Periodontol 58:266-273.

MOORE, W.E.C. (1987): Microbiology of Periodontal Disease, $J$ Periodont Res 22:335-341.

PIHLSTROM, B.L.; OLIPHANT, T.H.; and MCHUGH, R.B. (1984): Molar and Nonmolar Teeth Compared Over $61 / 2$ Years Following Two Methods of Periodontal Therapy, $J$ Periodontol 55:499-504.

RAMFJORD, S.P.; KNOWLES, J.W.; NISSLE, R.R.; SCHICK, R.A.; and BURGETT, F.G. (1973): Longitudinal Study of Petiodontal Therapy, $J$ Periodontol 44:66-77.

SAVITT, E.D.; STRZEMPKO, M.N.; VACCARO, K.K.; PEROS, W.J.; and FRENCH, C.K. (1988): Comparison of Cultural Methods and DNA Probe Analysis for the Detection of Actinobacillus actinomycetemcomitans, Bacteroides gingivalis and Bacteroides intermedius in Subgingival Plaque Samples, J Periodontol $59: 431-438$

SCHMIDT, E.F.; BRETZ, W.A.; HUTCHINSON, R.A.; and LOESCHE, W.J. (1988): Correlation of the Hydrolysis of Benzoyl-Arginine-Naphthylamide (BANA) by Plaque with Clinical Parameters and Subgingival Levels of Spirochetes in Periodontal Patients, J Dent Res 67:1505-1509.

SIMONSON, L.G.; GOODMAN, C.H.; BIAL, J.J.; and MORTON, H.E. (1988): Quantitative Relationship of Treponema denticola to Severity of Periodontal Disease, Infect Immun 56:726-728.

SUIDO, H.; NEIDERS, M.E.; BARUA, P.K.; NAKAMURA, M.; MASHIMO, P.A.; and GENCO, R.J. (1987): Characterization of N-CB,-glycyl-glycyl-arginyl Peptidase and Glycyl-prolyl Peptidase of Bacteroides gingivalis, J Periodont Res 22:412-418.

SYED, S.A.; GUSBERTI, F.A.; LOESCHE, W.J.; and LANG, N.P. (1984): Diagnostic Potential of Chromogenic Substrates for Rapid Detection of Bacterial Enzymatic Activity in Health and Disease Associated Periodontal Plaques, $J$ Periodont Res 19:618-621.

TALLY, F.P.; GOLDIN, B.R.; SULLIVAN, N.; JOHNSON, J.; and GORBACH, S.L. (1978): Antimicrobial Activity of Metronidazole in Anaerobic Bacteria, Antimicrob Agents Chemother 13:460-465.

WYSS, C. (1989): Dependence of Proliferation of Bacteroides forsythus on Exog. enous N-acetylmuramic Acid, Infect Immun 57:1757-1759.

ZAMBON, J.J.; REYNOLDS, H.S.; CHEN, P.; and GENCO, R.J. (1985): Rapid Identification of Periodontal Pathogens in Subgingival Dental Plaque. Comparison of Indirect Immunofluorescence Microscopy with Bacterial Culture for Detection of Bacteroides gingivalis, J Periodontol 56 (Suppl. 11):32-40. 